\title{
Determination of Diffusion and Mass Transfer Coefficients during Drying of Solvent-Absorbed Polymer Films
}

\author{
Kwang Seung PARK and Dukjoon $\mathrm{KIM}^{\dagger}$ \\ Department of Chemical Engineering, Sung Kyun Kwan University, Suwon, \\ Kyungki 440-746, Korea
}

(Received November 12, 1999)

\begin{abstract}
Mass transfer behavior during the drying process of solvent-absorbed polyimide films was investigated. Unsteady state mass balances were developed with a modified Fickian diffusion model involving temperature and concentration dependent diffusion coefficient, founded on Vrentas and Duda's hole free volume theory. Concentration profiles, solvent mass residue, and film thickness changes were obtained from numerical solution of mass transfer equations with moving boundary conditions. An interferometer system was used to measure the variation of film thickness during the drying process. Temperature and concentration dependence of diffusion coefficient and mass transfer coefficient were obtained from comparison of experimental observation and theoretical calculation.
\end{abstract}

KEY WORDS Drying Process / Diffusion Coefficient / Mass Transfer Coefficient / Polymer Films /

Thin polymer films have been applied in a variety of fields ${ }^{1,2}$ such as corrosion protective coatings, microlithography, packaging of semiconducting devices, membranes, and controlled drug delivery systems. One of the most common preparation techniques is the solvent casting method in which the solvent evaporates from polymer solution coated onto the substrate. The amount of solvent in the polymer films has significant influence on the final performance of films, sometimes leading to the deterioration of films due to cracking and delamination as well as unsatisfactory mechanical and thermal properties.

The continuous removal of solvent during the drying process of polymer films leads to the variation of solvent concentration distributions and solvent amount inside films, followed by variation of film thickness. In the actual film preparation processes, this behavior is mostly affected by thermal treatment schedules such as drying temperature, ramping rate, and aging process.

Diffusion and mass transfer coefficients are two major properties describing the mass transfer behavior in drying process. In polymer-solvent systems, diffusion coefficient is dependent on the concentration and temperature, and their dependence has been well described by free volume theory. Mass transfer coefficient is fundamentally not constant either, but dependent on the mass transfer rate. ${ }^{3}$ The constant mass transfer coefficient is defined for the convenience in the limit of zero mass transfer rate. Researchers usually assume or determine the constant value of mass transfer coefficient from analogies between heat and mass transfer, i.e., ChiltonColburn analogy, and use it to describe the drying process along with diffusion coefficient. As the mass transfer coefficient determined by this way might involve a few restrictive assumptions such as constant physical properties, fixed (small or high) rate of mass transfer, and no viscous dissipation, we determined the mass transfer coefficient from the actual drying behavior.

Theoretical analysis is represented with an appropri- ate model to describe the experimentally observed film thickness change during the isothermal drying process. Diffusion and mass transfer coefficients were extracted from the best fit of theoretical calculation to experimental data.

Polyimide films ${ }^{4-6}$ were used here. The temperature dependence of diffusion coefficient and the mass transfer coefficient properly determined from the present isothermal analysis is the fundamental to the prediction of mass transfer behavior in $N$-methylpyrrolidone (NMP)/ Polyimide (PI) systems for non-isothermal curing and drying.

\section{THEORY}

Solvent evaporation during film drying changes solvent concentration distributions inside films. As shown in Figure 1 where the $x$ axis indicates the normal direc-

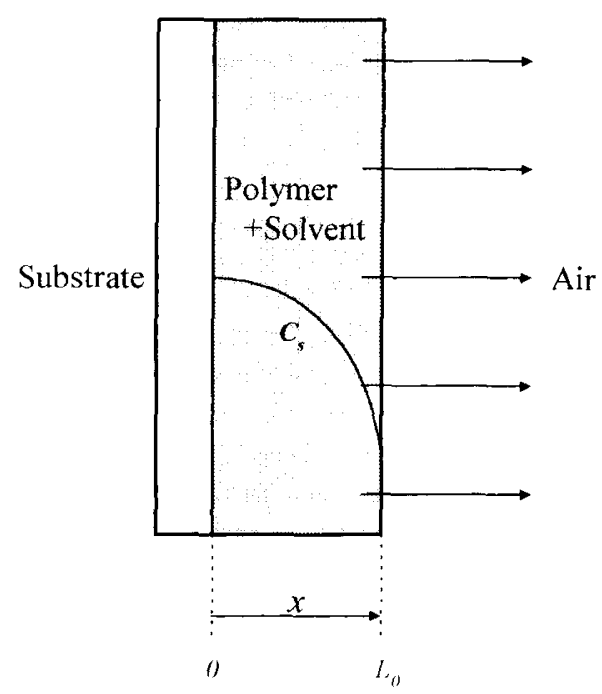

Figure 1. Representation of concentration profiles and boundary positions for one dimensional diffusion in thin polymer film.

\footnotetext{
${ }^{\dagger}$ To whom all correspondence should be addressed (Fax: 82-331-290-7272, E-mail: djkim@yurim.skku.ac.kr).
} 
tion from the polymer/substrate interface to film surface, the film thickness reduces as the solvent removes from the film. When the polymer film is very thin compared to width and length, the solvent diffusion and evaporation processes are assumed to take place in only one direction of $x$ axis. A simple model to describe this diffusion process is Fick's model ${ }^{7}$ where the solvent concentration of $C_{\mathrm{s}}$ inside film is expressed as a function of time, $t$ and $x$ as in eq 1.

$$
\frac{\partial C_{\mathrm{s}}}{\partial t}=\frac{\partial}{\partial x}\left(D-\frac{\partial C_{\mathrm{s}}}{\partial x}\right)-\frac{\mathrm{d} C_{\mathrm{s}}}{\mathrm{d} x} v
$$

where $v$ is the velocity of film/solvent bulk system and $D$ is the mutual diffusion coefficient.

Temperature and concentration dependence of diffusion coefficient is represented by the hole free volume theory of Vrentas and Duda. ${ }^{8-13}$ They provided free volume eq 2-4 in which eq 2 and 3 were applied to above $T_{\mathrm{g}}$ and eq 4 below $T_{\mathrm{g}}$ of solvent absorbed polymeric systems, respectively.

$$
\begin{gathered}
D=D_{0}\left(1-\phi_{1}\right)^{2}\left(1-2 \chi \phi_{1}\right) \exp \left[-\frac{-\gamma\left(\omega_{1} \hat{V}_{1}^{*}+\omega_{2} \xi \hat{V}_{2}^{*}\right)}{\hat{V}_{\mathrm{FH}}}\right] \\
\frac{\hat{V}_{\mathrm{FH}}}{\gamma}=\frac{K_{11}}{\gamma} \omega_{1}\left(K_{21}+T-T_{\mathrm{g} 1}\right)+\frac{K_{21}}{\gamma}\left(K_{22}+T-T_{\mathrm{g} 2}\right) \\
D(T)=D\left(T_{\mathrm{g} 2}\right) \exp \left[\frac{\gamma \hat{V}_{2}^{*} \xi}{K_{12}} \frac{T-T_{\mathrm{g} 2}}{K_{12}\left(\left(K_{22} / \lambda\right)+T-T_{\mathrm{g} 2}\right)}\right]
\end{gathered}
$$

Here, $D_{0}$ is pre-exponential factor, $\hat{V}_{1}^{*}$ specific critical hole free volume of pure solvent, $\hat{V}_{2}^{*}$ specific critical hole free volume of polymer, $T_{g}$, glass transition temperature of component $i, K_{11}$ and $K_{21}$ are free volume parameters for the solvent and $K_{12}$ and $K_{22}$ free volume parameters for the polymer, $\xi$ critical molar volume ratio of polymer to solvent, $\omega_{\mathrm{i}}$ weight fraction of component $i, \phi_{1}$ volume fraction of solvent, $\chi$ Flory-Huggins interaction parameter, and $\lambda$ volume contraction parameter attributed to glass transition.

The solution of eq 1 requires an initial and two boundary conditions. As the solvent concentration in the polymer film just after the casting process is uniform as $C_{0}$ through all film directions, the initial condition may be described by eq 5 .

$$
C_{\mathrm{s}}(x, 0)=C_{0}
$$

The boundary conditions are described by eq 6 and 7 . Equation 6 represents no concentration gradient at the polymer film/substrate interface, and eq 7 the diffusional mass flux from the polymer film surface is the same as mass flux driven by the vapor phase concentration difference in the boundary layer. As the mass flux at the film $\operatorname{surface}\left(x=L_{t}\right)$ is equivalent to the rate of total solvent mass reduction in the film due to the negligible solvent evaporation to $\mathrm{y}$ and $\mathrm{z}$ directions, eq 7 may be replaced by eq 8 .

$$
\frac{\partial C_{\mathrm{s}}}{\partial x}(0, t)=0 \quad \text { at } x=0
$$

$$
\begin{array}{cl}
D \frac{\partial C_{\mathrm{s}}}{\partial x}=-k^{\mathrm{G}}\left(P_{\mathrm{i}}-P_{\mathrm{b}}\right) & \text { at } x=L_{t} \\
D \frac{\partial C_{\mathrm{s}}}{\partial x}=\frac{1}{A} \frac{\mathrm{d} M_{\mathrm{s} t}}{\mathrm{~d} t} & \text { at } x=L_{t}
\end{array}
$$

In eq $7 k^{G}$ is the mass transfer coefficient in the boundary layer of vapor phase, $P_{\mathrm{i}}$ is the equilibrium partial pressure of solvent in the film surface, and $P_{\mathrm{b}}$ the partial pressure of solvent in the bulk atmosphere.

Once the variation behavior of solvent amount in the film during drying has been experimentally obtained, the right hand side of eq $8, \mathrm{~d} M_{\mathrm{st}} / \mathrm{d} t$, can be expressed as an appropriate functional form. In this case, the time and position dependence of solvent concentration in polymer films can be calculated using the governing eq 1 and an initial and two boundary conditions of eq 5,6 , and 8 , respectively.

The time dependence of solvent amount(mass) in the film, $M_{\mathrm{s} t}$ can be theoretically calculated from the integration of solvent concentration distribution at each time over the total film volume as in eq 9. The evolving film thickness, $L_{t}$ can be calculated from eq 10 , as the change of film thickness during the drying process is proportional to the change of residual solvent content inside the film.

$$
\begin{gathered}
M_{\mathrm{s} t}=A \int_{0}^{L_{t}} C_{\mathrm{s}} \mathrm{d} x \\
\frac{L_{t}}{L_{0}}=\phi_{20}+\phi_{10} \frac{M_{\mathrm{s} t}}{M_{\mathrm{s} 0}}
\end{gathered}
$$

where $A$ is the film surface area, $M_{\mathrm{s} 0}$ and $L_{0}$ are the initial solvent mass uptake in the system and initial film thickness, respectively, and $\phi_{20}$ and $\phi_{10}$ the initial volume fraction of polymer and solvent, respectively. The best fit of film thickness theoretically calculated to the one experimentally observed leads to the determination of diffusion coefficient. The mass transfer coefficient can be obtained from eq 7 .

\section{EXPERIMENTAL}

\section{Film Preparation}

Polyimide (PI) films were prepared on a silicon wafer using the precursor of PI, poly(amic acid) (PAA) with the chemical structure shown in Figure 2. $\langle 100\rangle$ type silicon wafer in the thickness of $360 \mu \mathrm{m}$ was provided by Hyundai Electronics Company and PAA (13.8 wt\%) was purchased from Du Pont Chemical Company. PAA was coated onto the silicon wafer using a spin coater (model 1-EC101DT-R485, Headway, USA) at the revolution speed of $1800 \mathrm{rpm}$ for $30 \mathrm{~s}$. Film-coated substrates were

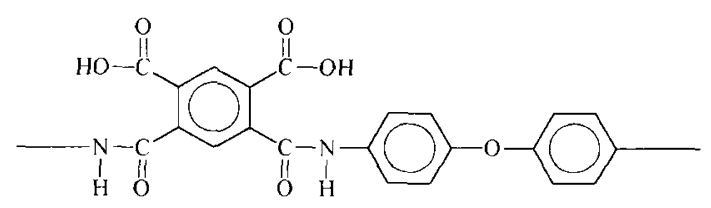

Figure 2. Chemical structure of poly(amic acid). 


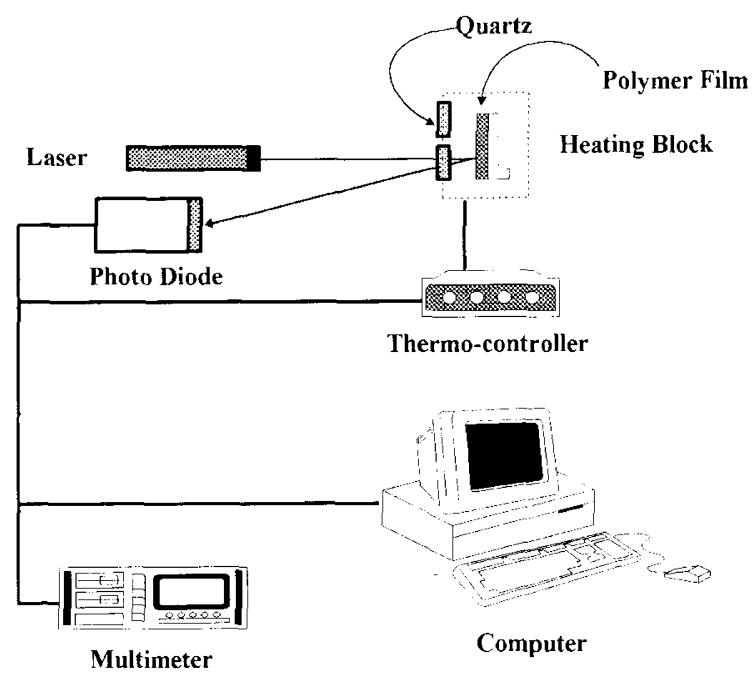

Figure 3. Schematic apparatus for measuring the thickness change of the polymer films using the interferometer system.

pre-baked at $8^{\circ} \mathrm{C}$ for $60 \mathrm{~min}$ to remove excess amount of NMP absorbed in films. Curing was performed by raising temperature from room temperature to $400^{\circ} \mathrm{C}$ at the ramping rate of $4^{\circ} \mathrm{C} \mathrm{min}{ }^{-1}$ in the nitrogen environment. Curing kinetics was investigated monitoring the characteristic IR band using FT-IR spectroscopy during the heating process. After curing, PI films were swollen in the NMP at 30,60 , and $80^{\circ} \mathrm{C}$, respectively. Film-coated substrates were periodically weighed until no weight change was observed to make sure the uniform concentration distribution in films. The equilibrium solvent mass uptake measured at the three different temperatures was used to determine the temperature dependence of $\chi$ value. Films swollen at $60^{\circ} \mathrm{C}$ were used for the film thickness measurement in the drying process.

\section{Film Thickness Measurement}

NMP-absorbed PI films were clamped vertically in a temperature controllable heating box with nitrogen gas purge line after the temperature had been stabilized by a temperature controller (Model 3000, LFE Instruments). Film thickness was measured under the slowly purged nitrogen gas atmosphere using an interferometer apparatus as shown in Figure 3 . The beam generated by $1 \mathrm{~mW}$ He-Ne laser with 632.8 wavelength (model 1507 0 , Uniphase, USA) was focused on a fixed spot of polymer film surface which is located in just above the clamp to neglect the beam bending effect caused by variation of film concentration. The intensity of laser beam reflected from the film was detected by a Silicone photodiode (model S2386-8 K, Hamamatsu, USA). Interfered sinusoidal intensity was monitored through a personal computer after digitalization by an A/D converting multimeter (model Fluke45, Fluke, Germany). All instruments were placed on the optical table (Edmund Scientific Co.) to reduce environmental noise. Film thickness measurements were isothermally performed in the black box to minimize the surrounding light effect at the three different drying temperatures of 30,60 , and $80^{\circ} \mathrm{C}$, respectively.

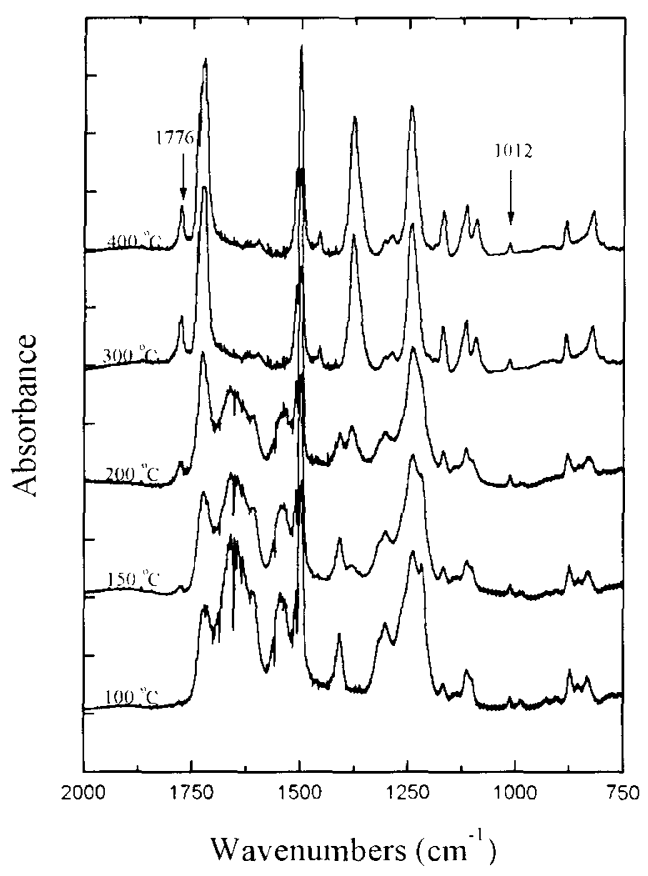

Figure 4. FT-IR spectra of PI films during the curing processe at the ramping rate of $4^{\circ} \mathrm{C} \mathrm{min}^{-1}$.

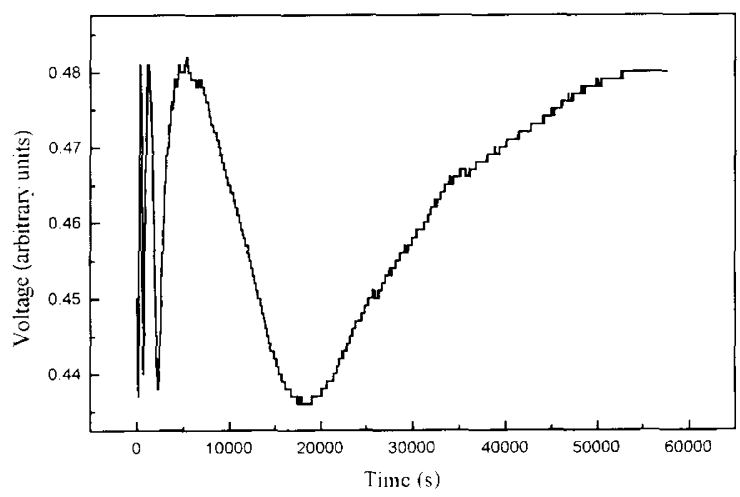

Figure 5. Voltage trace during the drying process of NMPabsorbed PI films at $30^{\circ} \mathrm{C}$.

\section{RESULTS AND DISCUSSION}

\section{Curing Process of PI Films}

Figure 4 shows variation of FT-IR spectra of PI films during curing. The characteristic band observed at 1776 $\mathrm{cm}^{-1}$ was attributed to the symmetric carbonyl stretching in imide group. This band appeared at temperatures above $100^{\circ} \mathrm{C}$ and its intensity increased with temperature. The band area at $1776 \mathrm{~cm}^{-1}$ was compared with the invariant (reference) one at $1012 \mathrm{~cm}^{-1}$ originating from aromatic vibration. Completion of curing process was assured from no further increase (change) in the band area ratio at $1776 \mathrm{~cm}^{-1}$ to at $1012 \mathrm{~cm}^{-1}$.

\section{Experimentally Measured Film Thickness Change}

Figure 5 shows the interfered beam intensity during the drying process of polymer films. Each interval between the consecutive maximum peaks corresponds to the reduction of film thickness of $0.216 \mu \mathrm{m}$, because it is 


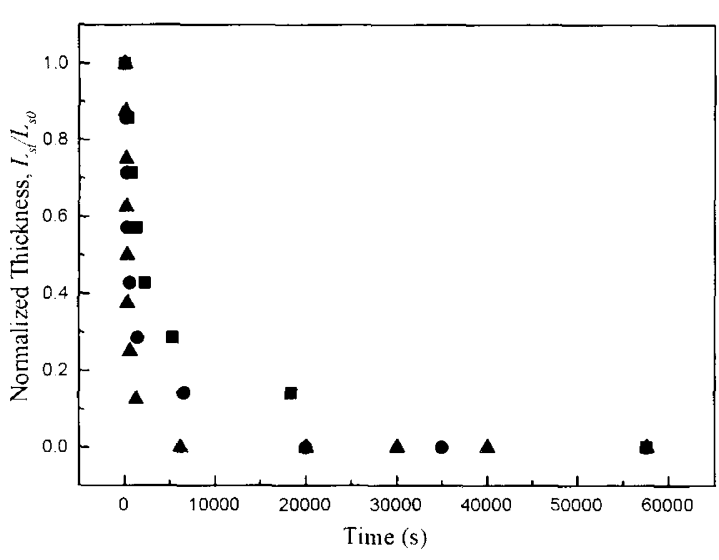

Figure 6. Variation of solvent film thickness during the drying process at different temperatures of $30(\square), 60(\bigcirc)$, and $80^{\circ} \mathrm{C}(\boldsymbol{\Delta})$, respectively.

related with the wavelength $(=632.8 \mathrm{~nm})$ of laser beam by eq $11^{14}$ when the refractive index of the film composed of binary mixture of polymer and solvent is assumed to be the volume-weighted average of the indices of its components.

$$
\Delta L_{t}=\lambda_{\text {beam }} / 2 n_{\text {sol }}
$$

where $\Delta L_{t}$ is the change of film thickness, $\lambda_{\text {beam }}$ the wavelength of laser beam, and $n_{\text {sol }}$ the refractive index of the solvent (NMP).

Figure 6 shows variation of the normalized solvent film thickness, obtained by dividing the film thickness difference at time $t\left(L_{\mathrm{s} t}=L_{t}-L_{0}\right)$ by the total film thickness $\left(L_{\mathrm{s} 0}=L_{\infty}-L_{0}\right)$. Film thickness reduced more rapidly with increasing temperatures.

For reference the total film thickness change during the drying process measured by this interferometric method was in good agreement with that obtained from weighing measurements performed before and after drying experiment.

\section{Polymer-Solvent Interaction Parameter}

The polymer-solvent interaction parameter, $\chi$ was determined from swelling experiments. The equilibrium concentration was obtained from the equilibrium mass uptake at different temperatures, and $\chi$ was calculated from the relationship with the solvent equilibrium volume fraction, $\phi_{1 \infty}$, by eq 12 suggested by Flory and Huggins. ${ }^{15}$ Figure 7 shows the resulting temperature dependence of equilibrium solvent mass uptake and $\chi$.

$$
\chi=\frac{\phi_{1 \infty}-1-\ln \phi_{1 \infty}}{\left(1-\phi_{1 \infty}\right)^{2}}
$$

\section{Free-Volume Parameters in Diffusion Coefficient}

Generally glass transition temperature of plasticized polymeric materials increases with decreasing solvent concentration. From the swelling experiment the equilibrium (maximum) NMP concentration absorbed in the cured PI film was about $20 \mathrm{wt} \%$. Thus, the glass transition temperatures of NMP/PI systems used in the drying experiments were higher than the experimental temperatures of 30,60 , and $80^{\circ} \mathrm{C}$, because the precursor of

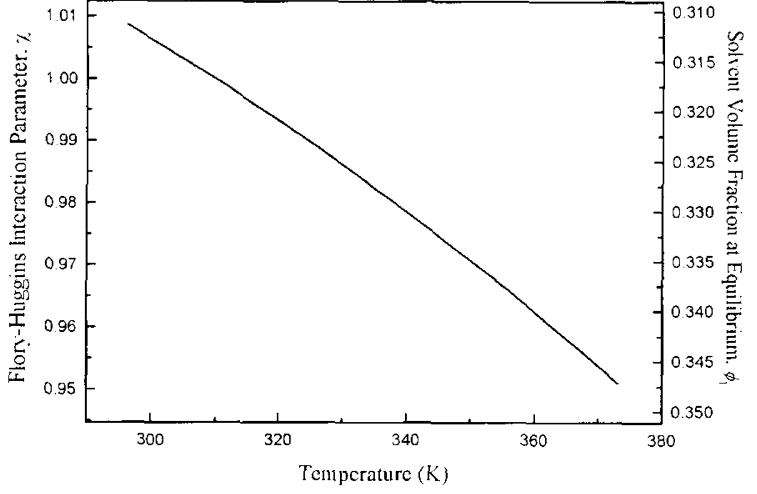

Figure 7. Temperature dependence of equilibrium solvent concentration and Flory-Huggins interaction parameter.

Table I. Free-volume parameters in the Vrentas-Duda's diffusion coefficient for the NMP/PI system

\begin{tabular}{ll}
\hline Parameters & \multicolumn{1}{c}{ Values } \\
\hline$D_{0}$ & $20.4786 \mathrm{~cm}^{2} \mathrm{~s}^{-1}$ \\
$K_{11} / \gamma$ & $0.0015976 \mathrm{~cm}^{3} \mathrm{~g}^{-1} \mathrm{~K}^{-1}$ \\
$K_{12} / \gamma$ & $0.0003064 \mathrm{~cm}^{3} \mathrm{~g}^{-1} \mathrm{~K}^{-1}$ \\
$K_{12}$ & $-8.81873 \mathrm{~K}$ \\
$K_{22}$ & $51.6 \mathrm{~K}$ \\
$T_{\mathrm{g} 1}$ & $140.98 \mathrm{~K}$ \\
$T_{\mathrm{g} 2}$ & $650.15 \mathrm{~K}$ \\
$\hat{V}_{1}^{*}$ & $0.773 \mathrm{~cm}^{3} \mathrm{~g}^{-1}$ \\
$\hat{V}_{2}^{*}$ & $0.635 \mathrm{~cm}^{3} \mathrm{~g}^{-1}$ \\
$\lambda$ & 0.0634 \\
$\xi$ & 0.3245 \\
\hline
\end{tabular}

PI, PAA, was reported to have the glass transition temperature of $119.5^{\circ} \mathrm{C}^{16}$ when the NMP concentration was $28.5 \mathrm{wt} \%$. In this case, the diffusion coefficient could be expressed by eq 4 according to the Vrentas and Duda's free volume theory. The diffusion coefficient at the glass transition temperature of polymer, $D\left(T_{\mathrm{g} 2}\right)$, in eq 4 could be determined by substitution of $T_{\mathrm{g} 2}$ for $T$ in eq 2 and 3 .

Several free volume parameters included in eq $2-4$ were determined. $T_{g 1}$ was determined from the temperature dependent viscosity behavior of NMP solvent. ${ }^{17} T_{\mathrm{g} 2}$ was obtained from the value reported by other investigators. ${ }^{18} \hat{V}_{1}^{*}$ was determined by the extrapolation of the specific volume of NMP solvent to $0 \mathrm{~K},{ }^{19}$ and $\hat{V}_{2}^{*}$ from the equivalence to $1.3 V_{\mathrm{w}}$, where van der Waals volume of $V_{\mathrm{w}}$ was determined from the group contribution theory $^{20} . K_{22}$ and $\gamma \hat{V}_{2}^{*} / K_{12}$ were determined from the Williams-Landel-Ferry relationship, ${ }^{10}$ and $K_{21}$ and $K_{11}$ from the relationship ${ }^{10}$ between $\left(T-T_{\mathrm{g} 1}\right)$ and $\left(T-T_{1}\right) / \mathrm{n}$ $\left[\eta_{1}\left(T_{1}\right) / \eta_{1}(T)\right]$. $\lambda$ were determined from the relationship between activation energy and free-volume parameters $^{10,11}$ and $\xi$ was obtained from its definition ${ }^{12}$ of $\hat{V}_{1}^{*}$ $M_{1} / \hat{V}_{2}^{*} M_{2}$. The values of all parameters except $D_{0}$ are summarized in Table I.

\section{Numerical Solution}

Variation in concentration in films during the drying process was predicted from numerical solution of eq $1-6$ and 8 . In order to simplify equations and their computa- 


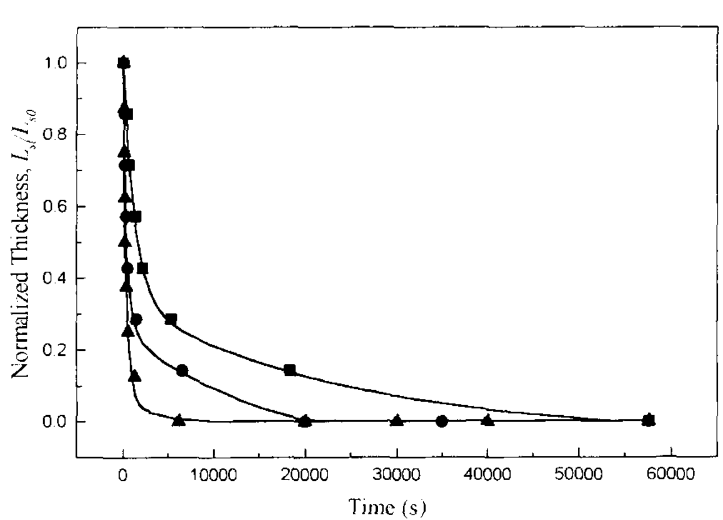

Figure 8. Comparison between the experimental observation (symbols) and the theoretical calculation (curves) for the time dependence of normalized film thickness at varying temperatures of $30(\boldsymbol{\square}), 60(\mathbf{)})$, and $80^{\circ} \mathrm{C}(\boldsymbol{\Delta})$, respectively.

tions, $C_{\mathrm{s}}, t$, and $x$ are normalized with $C_{0}, t_{0}\left(=L_{0}^{2} / D_{0}\right)$, and $L_{0}$. Solvent concentration at the film surface at each time step was determined using the boundary condition of eq 8. For its determination the variation rate of solvent amount in the film given by the right hand side eq 8 was obtained from the experimentally measured film thickness change shown in Figure 6. The numerical solution of governing eq 1 with a initial condition given by eq 5 and two boundary conditions given by eq 6 and 8 using the Crank-Nicholson's finite difference method ${ }^{21}$ led to time and position dependence of solvent concentration inside the film. The inward solvent concentrations from the film surface to substrate were successively calculated using the Gauss-Jordan elimination in which all finite difference equations involving position dependent concentrations were solved simultaneously with reduction in subdiagonal elements. ${ }^{21}$ The solvent mass residue in the film described by eq 9 was numerically solved using the Gaussian-Laguerre integration method. ${ }^{21} \mathrm{Fi}$ nally, film thickness was calculated from the fractional solvent mass residue in films according to eq 10 . In these calculations, total film thickness was divided into 100 sections and the time interval was $10^{-5} \mathrm{~s}$. These divisions were chosen, as no divergence in numerical computation was assured in case $\Delta t / \Delta x^{2}<0.5$ with computation time efficiency.

\section{Diffusion Coefficient}

Variation in film thickness theoretically calculated was fitted to the one experimentally observed by varying the pre-exponential factor, $D_{0}$. There should be a good accordance between the experimental and theoretical results when an appropriate value of diffusion coefficient is applied. As shown in Figure 8, the best fitting value of $D_{0}$ to adjust all experimental data measured at different temperatures was determined as $0.4768 \mathrm{~cm}^{2} \mathrm{~s}^{-1}$. The resulting temperature dependence of diffusion coefficient with this $D_{0}$ is shown in Figure 9 for a trace amount of solvent. Figure 10 shows the concentration profiles inside the polymer film, when the diffusion coefficient represented by Figure 9 was applied. The film surface moved to the substrate direction and the surface concentration reduced with drying time.

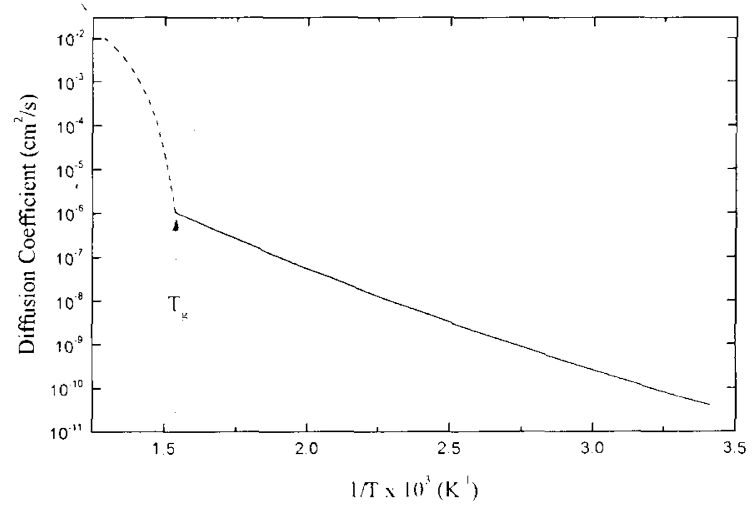

Figure 9. Temperature dependence of diffusion coefficient in the NMP/PI system. Dashed curve represents the diffusion coefficient above $T_{\mathrm{g}}$.

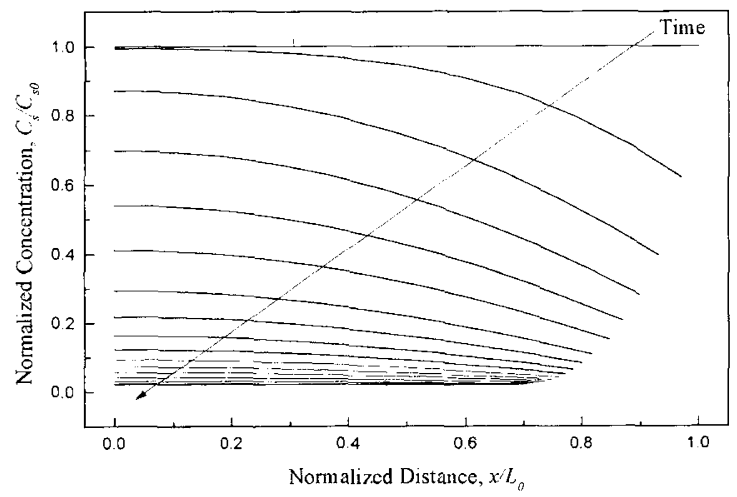

Figure 10. Solvent concentration profiles inside PI films during the drying process at $30^{\circ} \mathrm{C}$. The time interval between consecutive curves was $1500 \mathrm{~s}$.

\section{Mass Transfer Coefficient}

Mass flux dependence of mass transfer coefficient was obtained during drying. As the solvent partial pressure difference between the film surface and bulk phase, the driving force for the mass transfer in gas phase, is given by the solvent concentration at the film surface, the mass transfer coefficient also depends on the surface concentration. The equilibrium partial pressure of solvent at the film surface, $P_{\mathrm{i}}$, is related to the vapor pressure of solvent, $P_{\text {vap }}{ }^{22}$ and solvent concentration at the film surface, $\phi_{1}$ according to the Flory-Huggins theory ${ }^{15}$ as in eq 13. Solvent partial pressure at the bulk phase, $P_{\mathrm{b}}$, is actually nearly zero in the present analysis because the drying experiments were performed under nitrogen gas environment.

$$
P_{\mathrm{i}}=P_{\mathrm{vap}} \phi_{1} \exp \left[\phi_{2}+\chi\left(\phi_{2}\right)^{2}\right]
$$

where $\phi_{2}$ is the volume fraction of polymer.

The solvent partial pressure change in the surface boundary layer is shown in Figure 11. Solvent partial pressure decreased with decreasing solvent volume fraction at the film surface, and the dependence was more significant at higher temperatures. The temperature and surface concentration dependence of mass transfer coefficient and mass transfer rate was obtained from eq 7 and shown in Figure 12. The magnitude of mass trans- 


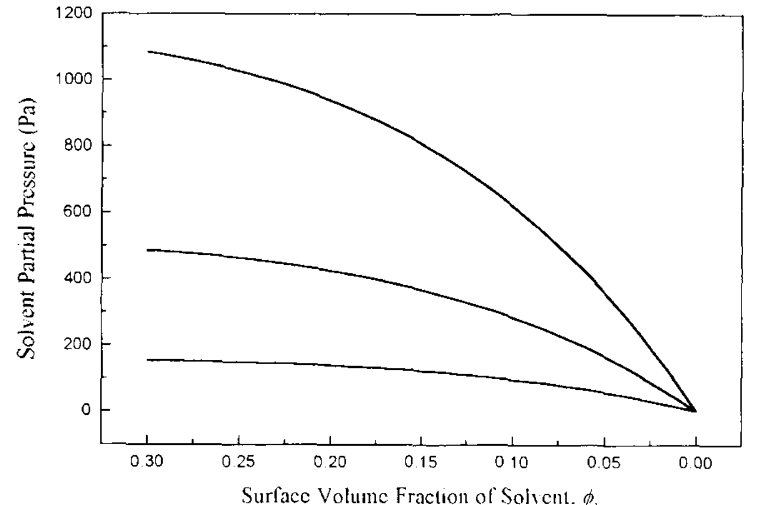

Figure 11. Surface concentration dependence of solvent partial pressure in the film surface boundary layer during the drying process at varying temperatures of 30,60 , and $80^{\circ} \mathrm{C}$ (from bottom to top).

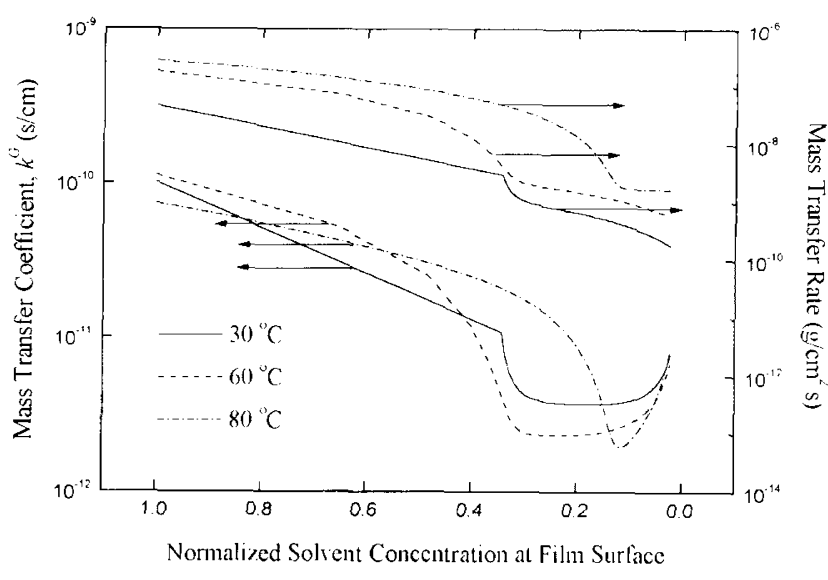

Figure 12. Surface concentration dependence of mass transfer coefficient and mass transfer rate in the NMP/PI system at 30,60 , and $80^{\circ} \mathrm{C}$.

fer coefficient decreased from about $10^{-10}$ to $10^{-12} \mathrm{~s}$ $\mathrm{cm}^{-1}$ with decreasing solvent concentration at the film surface.

Mass transfer coefficient calculated by this method has finite values, until the driving force of gas phase mass transfer, $\Delta P\left(=P_{i}-P_{\mathrm{b}}\right)$, given by the right hand side of eq 7 decreases to near zero, because the mass transfer rate at film surface given by the left-hand side of eq 7 also drops to nearly zero. The mass transfer coefficient illustrated deviations from the finite values when $\Delta P$ or film surface concentration is very close to zero, due to decimal place limitations, i.e., round-off error.

Figure 13 summarizes computations for diffusion and mass transfer coefficients from theoretical equations and experimental data.

\section{CONCLUSIONS}

The film thickness change during drying of the swollen PI films was observed using interferometer system and its behavior was theoretically analyzed with the modified Fickian diffusion model. The rate of film thickness change decreased with increasing drying temperature. The diffusion coefficient extracted from this analysis increased from $6.7 \times 10^{-11}$ to $5.7 \times 10^{-10} \mathrm{~cm}^{2} \mathrm{~s}^{-1}$ with

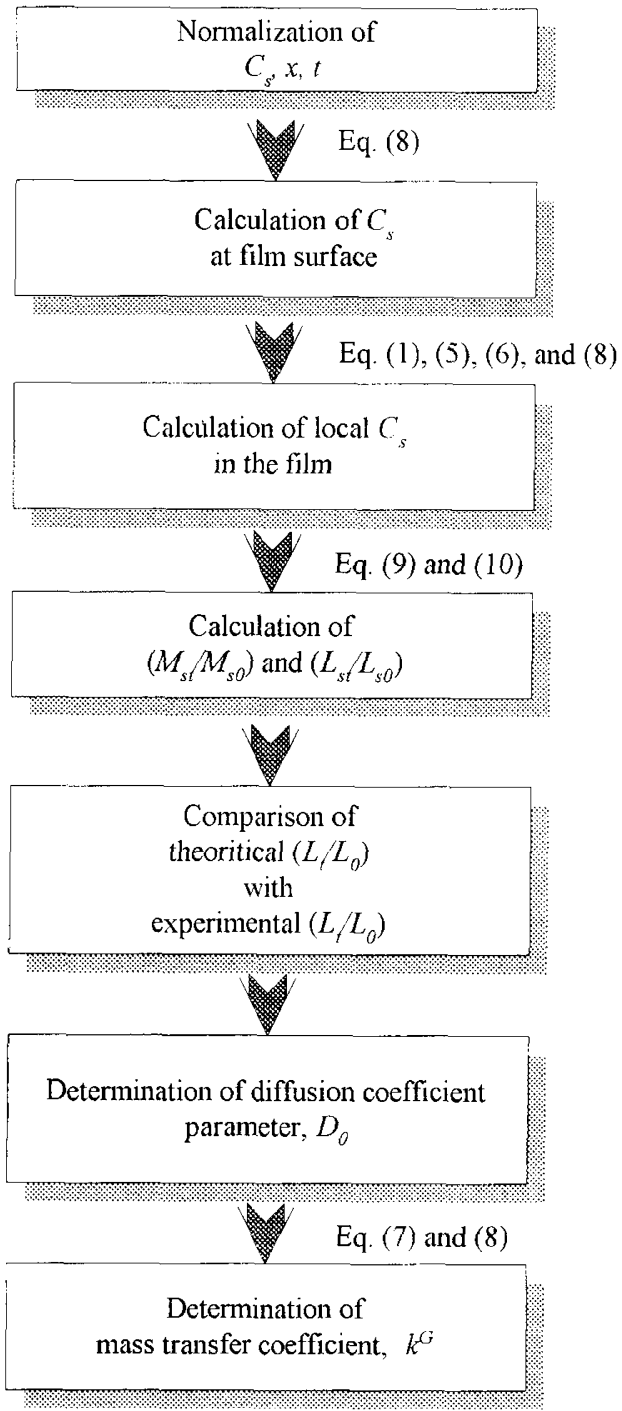

Figure 13. Overall computation procedure for determination of diffusion and mass transfer coefficients.

temperature from 30 to $80^{\circ} \mathrm{C}$. As drying in this system proceeded below glass transition temperature, solvent concentration effect on the diffusion coefficient was not significant. Mass transfer coefficient was from $10^{-12}$ to $10^{-10} \mathrm{~s} \mathrm{~cm}^{-1}$ in this experimental range, depending on the mass transfer rate or solvent concentration at the film surface.

Acknowledgment. This work was supported by the Korea Science and Engineering Foundation Grant 9811109-050-2.

\section{LIST OF SYMBOLS}

Symbols :

$A$, Film surface area $\left[\mathrm{cm}^{2}\right]$

$C_{\mathrm{s}}$, Solvent concentration inside film $\left[\mathrm{g} \mathrm{cm}^{-3}\right.$ ]

$C_{\mathrm{s} 0}$, Initial solvent concentration inside film $\left[\mathrm{g} \mathrm{cm}^{-3}\right]$

$D$, Mutual diffusion coefficient $\left[\mathrm{cm}^{2} \mathrm{~s}^{-1}\right]$

$D_{0}, \quad$ Pre-exponential factor $\left[\mathrm{cm}^{2} \mathrm{~s}^{-1}\right]$

$K_{11}$, Solvent free-volume parameter $\left[\mathrm{cm}^{3} \mathrm{~g}^{-1} \mathrm{~K}^{-1}\right]$

$K_{12}$, Polymer free-volume parameter $\left[\mathrm{cm}^{3} \mathrm{~g}^{-1} \mathrm{~K}^{-1}\right.$ ] 
$K_{21}$, Solvent free-volume parameter [K]

$K_{22}$, Polymer free-volume parameter [K]

$k^{\mathrm{G}}$, Mass transfer coefficient in the gas phase boundary layer $\left[\mathrm{s} \mathrm{cm}^{-1}\right.$ ]

$L_{0}, \quad$ Initial film thickness $[\mu \mathrm{m}]$

$L_{\mathrm{s} t}$, Film thickness attributed to the presence of solvent at arbitrary drying time, $t[\mu \mathrm{m}]$

$L_{t}$, Film thickness at arbitrary drying time, $t[\mu \mathrm{m}]$

$L_{\infty}, \quad$ Film thickness at infinite drying time $[\mu \mathrm{m}]$

$M_{1}$, Molecular weight of solvent [ $\mathrm{g} \mathrm{mol}^{-1}$ ]

$M_{2}$, Molecular weight of polymer jumping unit [g $\mathrm{mol}^{-1}$ ]

$M_{\mathrm{s} t}$, Mass uptake of solvent in swollen film at arbitrary drying time, $t[\mathrm{~g}]$

$M_{\mathrm{s} 0}$, Initial mass uptake of solvent in swollen film [g]

$n_{\text {sol }}$, Refractive index of the solvent

$P_{\mathrm{b}}, \quad$ Partial pressure of solvent in the bulk atmosphere [Pa]

$P_{\mathrm{i}}, \quad$ Equilibrium partial pressure of solvent at the film surface $[\mathrm{Pa}]$

$P_{\text {atm }}$, Atmospheric pressure [Pa]

$P_{\text {vap }}$, Vapor pressure of solvent $[\mathrm{Pa}]$

$R, \quad$ Gas constant $\left[\mathrm{kJ} \mathrm{mol}^{-1} \mathrm{~K}^{-1}\right]$

$T$, Temperature [K]

$T_{1}$, Convenient reference temperature [K]

$T_{\mathrm{g} 1}$, Glass transition temperature of pure solvent [K]

$T_{\mathrm{g} 2}, \quad$ Glass transition temperature of polymer [K]

$t$, Time [s]

$\hat{V}_{1}^{*}$, Specific critical hole free volume of pure solvent required for jump $\left[\mathrm{cm}^{3} \mathrm{~g}^{-1}\right]$

$\hat{V}_{2}^{*}$, Specific critical hole free volume of polymer required for jump $\left[\mathrm{cm}^{3} \mathrm{~g}^{-1}\right.$ ]

$V_{\mathrm{W}}$, van der Waals volume $\left[\mathrm{cm}^{3} \mathrm{~g}^{-1}\right]$

$\hat{V}_{\mathrm{FH}}$, Average hole free volume of mixture $\left[\mathrm{cm}^{3} \mathrm{~g}^{-1}\right]$

$v, \quad$ Velocity of film/solvent bulk system $\left[\mathrm{cm} \mathrm{s}^{-1}\right]$

$x$, Distance from the substrate/film interface to film surface $[\mu \mathrm{m}]$

$\chi$, Flory-Huggins interaction parameter

$\phi_{1}, \quad$ Volume fraction of solvent

$\phi_{2}$, Volume fraction of polymer

$\phi_{10}, \quad$ Initial volume fraction of solvent

$\phi_{20}, \quad$ Initial volume fraction of polymer

$\phi_{1 \infty}, \quad$ Equlibrium volume fraction of solvent

$\gamma$, Overlap factor which accounts for shared free volume

$\eta_{1}, \quad$ Viscosity of solvent $\left[\mathrm{g} \mathrm{cm}^{-1} \mathrm{~s}^{-1}\right]$

$\lambda$, Parameter to characterize the volume contraction change attributed to the glass transition

$\lambda_{\text {beam }}$, Wavelength of laser $[\mu \mathrm{m}]$

$\omega_{1}$, Weight fraction of solvent

$\omega_{2}$, Weight fraction of polymer

$\xi$, Ratio of critical molar volume of solvent jumping unit to that of polymer jumping unit

\section{REFERENCES}

1. C. C. Chao and K. D. Scholz, Proc. 38th Electronic Component Conference, 276 (1998).

2. R. A. Larsen, IBM J Res Dev, 26, 268 (1980).

3. R. Bird, W. E. Stewart, and E. N. Lightfoot, "Transport Phenomena”, John Wiley \& Sons, New York, N.Y., 1960, Chapter 21 , pp $636-642$.

4. H. Satou and D. Makino, "Polyimides for Electric Applications", Hitachi Chemical Co Ltd, Ibaraki, Japan, 1993.

5. J. C. Coburn and M. T. Pottiger, "In Polyimides : Fundamentals and Applications", M. K. Ghosh and K. L. Mittal Ed., Marcel Dekker, New York, N.Y., 1996, pp 207-247.

6. K. Sato, K. Mukai, S. Harada, A. Saeki, T. Kimura, T. Okubo, I. Ishi, and I. Shimizu, IEEE Trans on Hybrid and Packaging, PHP-9, 173 (1973).

7. R. B. Bird, W. E. Stewart, and E. N. Lightfoot, "Transport Phenomena", Part III, John Wiley \& Sons, New York, N.Y. 1960.

8. J. S. Vrentas and C. M. Vrentas, J. Polym. Sci., Polym. Phys. Ed., 32, 187 (994).

9. J. S. Vrentas, J. L. Duda, H. C. Ling, and A. C. Hou, J. Polym. Sci., Polym. Phys. Ed., 23, 289 (1985).

10. J. S. Vrentas, J. Appl. Polym. Sci., 25, 1297 (1980).

11. J. S. Vrentas, J. Appl. Polym. Sci., 22, 2325 (1978).

12. J. S. Vrentas, J. Polym. Sci., Polym. Phys. Ed., 15, 403 (1977).

13. J. M. Zielinski and J. L. Duda, AIChE J., 38, 405 (1992).

14. K.L. Saenger and H-M. Tong, "In New Characterization Techniques for Thin Polymer Films" H-M. Tong and L. T. Nguyen Ed., John Wiley \& Sons, New York, N.Y., 1990, p 95.

15. P. J. Flory, "Principles of Polymer Chemistry" Cornell University Press, Ithaca, New York, N.Y., 1971.

16. S. I. Kim, S. M. Pyo, and M. Ree, Macromolecules, 30, 7890 (1997).

17. A. J. Barlow, J. Lamb, and A. J. Matheson, Proc. Roy. Soc. A, 292, 322 (1966).

18. M. I. Bessonov, M. M. Koton, V. V. Kudryavtsev, and L. A. Laius, "Polyimides, Thermally Stable Polymers", Consultants Bureau, New York, N.Y., 1987.

19. D. R. Lide, "Handbook of Chemistry and Physics" 78th ed, CRC Press, New York, N.Y., 1997.

20. D. W. Van Krevelen, "Properties of Polymers", 3rd ed, Elservier Science, Netherlands, 1990.

21. B. Carnahan, H. A. Luther, and J. O. Wilkes, "Applied Numerical Methods", John Wiley \& Sons, New York, N.Y., 1969.

22. C. L. Yaw, "Handbook of Vapor Pressure", Vol. 2, Gulf Publishing, Houston, Texas, 1994, p 39. 